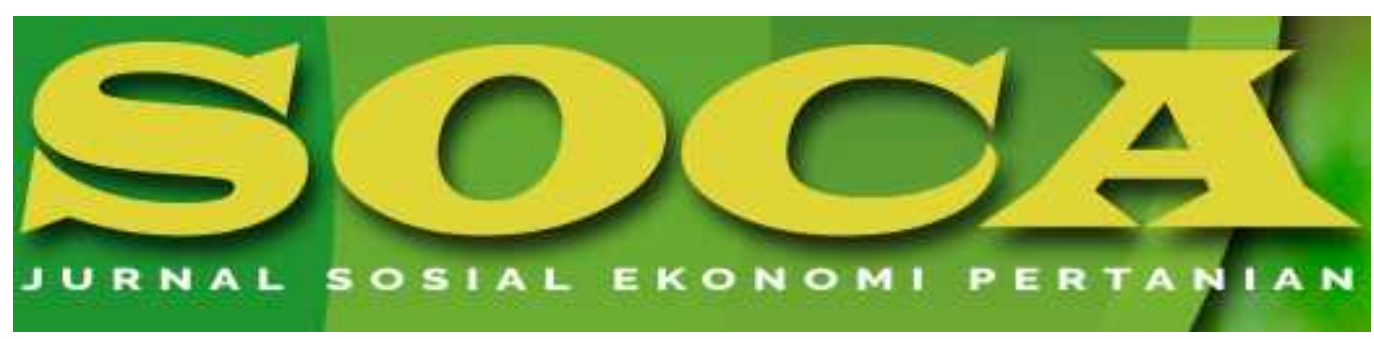

https://ojs.unud.ac.id/index.php/soca

\title{
ANALISIS PERMINTAAN CABAI RAWIT MERAH (Capsicum frutescens) DI KABUPATEN SEMARANG
}

\author{
Lea Miftahuddin, Titik Ekowati dan Bambang Mulyatno Setiawan \\ Program Studi S1 Agribisnis, Departemen Pertanian, \\ Fakultas Peternakan dan Pertanian, Universitas Diponegoro \\ Email : leamiftahuddin@gmail.com \\ HP : 085851873698
}

\begin{tabular}{l} 
Kata Kunci: \\
cabai rawit \\
merah, \\
elastisitas \\
permintaan, \\
faktor permintaan \\
\hline
\end{tabular}

\begin{abstract}
Abstrak
Cabai rawit merah merupakan bahan masakan yang mempunyai permintaan yang tinggi di tingkat konsumen rumah tangga. Permintaan cabai rawit merah dipengaruhi oleh beberapa faktor. Faktor - faktor permintaan cabai rawit merah antara lain harga cabai rawit merah, harga cabai merah keriting, pendapatan konsumen rumah tangga, jumlah anggota keluarga konsumen dan selera konsumen. Penelitian ini bertujuan untuk menganalisis faktor-faktor yang mempengaruhi permintaan cabai rawit merah dan untuk menganalisis elastisitas permintaan cabai rawit merah di Kabupaten Semarang. Lokasi penelitian dilakukan secara purposive. Metode yang digunakan adalah metode survei dan pemilihan sampel ditentukan dengan metode quota sampling dengan memilih sebanyak 90 responden dari 3 kecamatan di Kabupaten Semarang dengan produksi cabai rawit paling tinggi, sedang dan paling rendah. Pengambilan responden menggunakan metode snowball. Data dianalisis dengan regresi linier berganda. Hasil analisis regresi linier berganda menunjukan bahwa variabel - variabel bebas secara serempak berpengaruh nyata terhadap variabel terikat. Secara parsial pendapatan konsumen, jumlah anggota keluarga dan selera konsumen berpengaruh terhadap permintaan cabai rawit merah. Sedangkan harga cabai rawit merah dan harga cabai merah keriting tidak berpengaruh terhadap permintaan cabai rawit merah. Elastisitas harga cabai rawit merah bersifat inelastis 0,135 sehingga termasuk kategori barang normal. Elastisitas pendapatan sebesar 0,317. Cabai merah keriting merupakan barang pengganti cabai rawit merah dengan elastisitas 0,122 .
\end{abstract}


DEMAND ANALISYS FOR RED CAYENNE PEPPER IN SEMARANG REGENCY

\section{Keywords: red} cayenne pepper, elasticity of demand, demand factors

\begin{abstract}
Abstrak
Red cayenne papper is a food ingredient that has a high demand at the level of household consumers. Demand for red cayenne is influenced by several factors. Factors demand for red cayenne papper were red cayenne papper prices, curly red chili prices, household consumer income, number of family members and consumer tastes. The research aimed to analyze the determinant factors of red cayenne papper demand and to analyze elasticity of demand of red cayenne pepper in Semarang Regency. The research location determined by purposive. Survey method was used with Quota sampling to select 90 respondents from 3 District in Semarang Regency with the criteria of highest, medium and low red cayenne pepper production. Respondents taken by snowball method. Data were analyzed using multiple linear regression. Regression analyzed showed that independent variabels simultaneosly significant on dependent variabel. Partially the income of consumers, the number of family members and consumer tastes significantly influence the demand for red cayenne pepper. While the price of red cayenne pepper and curly red chili did not significantly affect the demand for red cayenne pepper. Red cayenne pepper elasticity was elastic 0.135 and categorized as normal goods. The income elasticity was 0.317. Curly red chili was substitutes red cayenne pepper with elasticity 0.122.
\end{abstract}

How to Cite (APA 6th Style):

Miftahuddin, L., Ekowati, T., \& Setiawan, B. M. (2020). Analisis Permintaan Cabai Rawit Merah (Capsicum Frutescens) di Kabupaten Semarang. SOCA: Jurnal Sosial Ekonomi Pertanian, 14(1), 66-75.

https://doi.org/https://doi.org/10.24843/SOCA.2020.v14.i01.p06

\section{PENDAHULUAN}

Cabai termasuk jenis tanaman hortikultura yang banyak dibudidayakan di Indonesia dengan tingkat permintaan tinggi. Harga jual cabai relatif tinggi dan mempunyai manfaat yang banyak. Cabai mengandung capcaicin dan lasparaginase yang dapat mencegah penyakit kanker. Cabai juga mengandung vitamin A, vitamin $\mathrm{C}$ dan kalsium (Prajnata, 2001). Cabai dimanfaatkan untuk bumbu masakan, industri makanan dan peternakan (Setiadi, 2008).Cabai merupakan kebutuhan masyarakat sehari-hari, sehingga volume ketersediaan cabai dipasaran sangat banyak.

Kota atau kabupaten dengan penduduk satu juta jiwa atau lebih mempunyai kebutuhan cabai sekitar 800.000 ton/tahun atau 66.000 ton/bulan. Musim hajatan dan hari besar biasanya kebutuhan cabai meningkat $10-20 \%$ dari. Bertambahnya luas panen mengakibatkan produksi cabai rawit cenderung mengalami peningkatan sejak tahun 1998-2017, akan tetapi persediaan cabai rawit cenderung fluktuatif 
karena waktu puncak panen yang tidak teratur setiap tahunnya (Pusat Data dan Sistem Informasi Pertanian, 2018). Fluktuasi produksi cabai disebabkan oleh musim tanam dan faktor lingkungan. Fluktuasi ini yang menyebabkan harga jual cabai dipasaran tidak stabil dan menjadikan cabai sebagai tiga besar komoditas yang menyebabkan terjadinya inflasi di Indonesia.

Produksi cabai rawit merah di Kabupaten Semarang sebanyak 95,23 ton. Kabupaten Semarang berada di nomor 5 sebagai kabupaten dengan produksi cabai rawit di Provinsi Jawa Tengah setelah Kabupaten Banjarnegara, Kabupaten Boyolali, Kabupaten Brebes dan Kabupaten Rembang. Kebutuhan konsumsi cabai rawit di Kabupaten Semarang pada tahun 2017 sebesar 1,59 kg/kap/th (Badan Pusat Statistika Kabupaten Semarang, 2018)

Berdasarkan penelitian terdahulu oleh Astami (2018) diperoleh hasil bahwa harga cabai rawit merah, harga bawang putih, pendapatan rumah tangga dan jumlah anggota keluarga berpengaruh terhadap permintaan cabai rawit merah di Kota Surakarta sedangkan harga bawang merah dan harga cabai keriting tidak berpengaruh terhadap permintaan cabai rawit merah. Elastisitas harga adalah sebesar -0,150 atau < 1 bersifat inelastis, elastisitas silang bawang putih adalah sebesar -0,050 bersifat komplementer dan elastisitas pendapatan bernilai -0,139 berarti cabai rawit merah termasuk barang inferior.

Penelitian oleh Yanti (2019) menunjukan hasil bahwa variabel jumlah anggota keluarga mempengaruhi permintaan cabai rawit di Kota Denpasar Provinsi Bali sedangkan variabel harga barang itu sendiri, harga barang lain dan pendapatan rumah tangga konsumen tidak berpengaruh. Elastisitas harga bernilai 0 berarti inelastis sempurna. Elastisitas silang bernilai 0 dan elastisitas pendapatan bernilai 0 berarti cabai rawit bersifat inelastis terhadap pendapatan.

Penelitian Palar (2016) diperoleh hasil bahwa variabel harga cabai rawit, harga barang lain dan selera masyarakat berpengaruh terhadap permintaan cabai rawit di Kota Manado. Nilai elastisitas harga cabai rawitdi Kota Manado sebesar 0,032 atau $<1$ yang berarti inelastis.

Produksi cabai rawit di Kabupaten Semarang yang menjadi produk tanaman pangan yang banyak digunakan sebagai bahan utama masakan. Hal ini membuat peneliti tertarik untuk menganalisis faktor yang berpengaruh terhadap permintaan cabai rawit merah di Kabupaten Semarang. Penelitian ini dibutuhkan untuk memprediksi kebutuhan konsumsi cabai rawit oleh para pengambil kebijakan dan dampak terhadap perubahan harga, harga barang lain, jumlah anggota keluarga serta pendapatan keluarga konsumen terhadap permintaan cabai rawit merah.

Tujuan dari penelitian ini adalah menganalisis faktor harga cabai rawit merah, harga cabai merah keriting, pendapatan keluaga konsumen, jumlah anggota keluarga konsumen serta selera konsumen terhadap permintaan cabai rawit merah dan menganalisis elastisitas permintaan cabai rawit merah di Kabupaten Semarang.

\section{METODE PENELITIAN}

Penelitian telah dilakukan pada bulan Agustus sampai Oktober 2019 di Kabupaten Semarang. Metode penentuan lokasi penelitian menggunakan metode purposive atau sengaja. Metode penelitian yang dipakai yaitu metode survei atau mengambil beberapa sampel dari suatu populasi. Metode pengambilan sampel ditentukan dengan metode quota sampling yaitu memilih sebanyak 90 responden 
dari 3 kecamatan di Kabupaten Semarang dengan produksi cabai rawit paling banyak, produksi sedang dan produksi paling sedikit. Metode snowball digunakan untuk mengambil responden.

Data penelitian yang telah dilakukan adalah data primer dan data sekunder. Hasil wawancara dan pengamatan secara langsung terhadap responden merupakan data primer. Data sekunder diperoleh Badan Pusat Statistika dan berbagai literatur yang relevan terhadap penelitian ini seperti jurnal dan buku. Analisis regresi digunakan untuk menganalisis data yang sudah dikumpulkan. Persamaan regresi digambarkan yaitu :

$$
\mathrm{Y}=\mathrm{a}+\mathrm{b}_{1} \mathrm{X}_{1}+\mathrm{b}_{2} \mathrm{X}_{2}+\mathrm{b}_{3} \mathrm{X}_{3}+\mathrm{b}_{4} \mathrm{X}_{4}+\mathrm{b}_{5} \mathrm{D}+\mathrm{e}
$$

Keterangan :

$\mathrm{Y}=$ Jumlah permintaan cabai rawit merah di Kabupaten Semarang (Kg/bulan)

a $\quad=$ Konstanta

$\mathrm{b} \quad=$ Koefisien regresi

$\mathrm{X} 1=$ Variabel harga cabai rawit merah $(\mathrm{Rp} / \mathrm{kg})$

$\mathrm{X} 2=$ Variabel harga cabai merah keriting $(\mathrm{Rp} / \mathrm{kg})$

$\mathrm{X} 3=$ Variabel pendapatan $(\mathrm{Rp} / \mathrm{bln})$

$\mathrm{X} 4 \quad$ = Variabel jumlah anggota keluarga (jiwa)

$\mathrm{D}=$ Dummy atau selera $($ Suka $=1$ atau kurang suka $=0)$

e $\quad=$ error

Uji Anova atau uji $\mathrm{F}$ bertujuan menganalisis variabel independen secara bersama - sama mempuyai pengaruh terhadap variabel terikat yaitu pemintaan cabai rawit (Santoso, 2009). Diajukan hipotesis yaitu :

a. Ho : $b_{1}=b_{2}=\ldots=b_{n}=0$, variabel independen secara serempak bukan sebagai penjelas yang signifikan terhadap variabel dependen.

b. Hi : $b_{1} \neq b_{2} \neq \ldots \neq \neq b_{n} \neq 0$,variabel independen secara serempak sebagai penjelas dari variabel dependen.

Pengambilan keputusan didasarkan jika :

a. Nilai Sig. $\leq 0,05$, Ho ditolak dan Hi diterima, berarti variabel bebas secara serempak merupakan penjelas yang signifikan terhadap variabel terikat.

b. Nilai Sig. > 0,05, Ho diterima dan Hi ditolak, variabel indepeden secara bersama sama bukan sebagai penjelas dari variabel dependen.

Uji t dilakukan uji kebenaran atau kepalsuan variabel independen secara individu dari variabel terikat (Ghozali, 2011). Diajukan hipotesis yaitu :

a. Ho : $b_{1}=0, b_{2}=0 \ldots \ldots b_{n}=0$, variabel independen tidak memiliki pengaruh relevan dengan variabel dependen.

b. Hi : $b_{1} \neq 0, b_{2} \neq 0 \ldots \ldots . \neq b_{n} \neq 0$, variabel independen berpengaruh relevan dengan variabel dependen. 
Pengambilan keputusan didasarkan jika :

a. Nilai Sig. $\leq 0,05$, Ho ditolak dan Hi diterima berarti setiap variabel independen memiliki pengaruh parsial dengan variabel dependen.

b. Nilai Sig. > 0,05, Ho diterima dan Hi ditolak artinya setiap variabel independen tidak memiliki pengaruh parsial dengan variabel dependen.

Uji koefisien determinasi untuk menjelaskan variasi variabel independen terhadap variabel dependen untuk menilai skala ragam variabel dependen yang digambarkan dari variabel independen. Nilai koefisien determinasi bisa dinilai dari nilai R-Square atau Adjusted R-Square. Nilai koefisien determinasi $\left(\mathrm{R}^{2}\right)$ adalah antara nol sampai satu (Sinambela, et al., 2014). Variabel independen menjelaskan hampir seluruh keterangan yang dipakai memprediksi variabel dependen apabila nilai $\mathrm{R}^{2}$ mendekati 1 (Cahmayati dan Hadi, 2009).

\section{HASIL DAN PEMBAHASAN}

\section{Karakteristik Responden}

Responden adalah ibu rumah tangga dan dibatasi hanya pada orang dewasa yang sudah mempunyai pendapatan atau mengetahui pendapatan keluarga. Berdasarkan hasil wawancara diketahui bahwa sebesar 33,33\% reponden berusia 51-60 tahun. Pendidikan terakhir responden sebanyak 44,44\% adalah SMA. Sebanyak 60\% responden bekerja sebagai ibu rumah tangga. Responden memilih membeli cabai rawit merah 1 - 10 kali sebanyak 43,33\% dan sebesar 54,44\% memilih membeli di sayur keliling dengan rata-rata permintaan sebanyak 0,81 $\mathrm{kg} /$ bulan. hal ini dikarenakan pertimbangan jarak dari rumah dan tidak semua responden pergi ke pasar tradisional. Diketahui bahwa sebanyak 55,56\% responden berpendapatan $>$ Rp 2.000.000 - Rp 3.000.000.

\section{Analisis Regresi Linier Berganda}

Analisis regresi linier berganda untuk menguji hipotesis dengan persaman yang sudah dimodelkan sehingga persamaan yang diperoleh :

$$
Y=-3,163+1,387 \mathrm{E}-6 \mathrm{X}_{1}+1,396 \mathrm{E}-6 \mathrm{X}_{2}+9,566 \mathrm{E}-8 \mathrm{X}_{3}+0,167 \mathrm{X}_{4}+0,889 \mathrm{X}_{5}
$$

Berdasarkan hasil analisis diperoleh hasil nilai sig. F sebesar 0,00. Nilai sig. F lebih keci dari derajat signifikansi yaitu $5 \%$ atau 0,05 , kemudian bisa ditarik kesimpulkan $\mathrm{H} 1$ diterima dan $\mathrm{HO}$ ditolak. Hal tersebut dapat diartikan adanya dampak relevan antara X1,X2, X3, X4 dan X5 terhadap permintaan cabai rawit merah di Kabupaten Semarang. Hal ini sesuai dengan pendapat Zaenuddin (2015) uji $\mathrm{F}$ dilakukan guna mengetahui seluruh variabel independen apakah memiliki pengaruh simultan terhadap variabel dependen. Sesuai pendapat Kuncoro (2009) bahwa jika nilai signifikansi $<0,05$ atau $F$ hitung $>F$ tabel, variabel independen secara simultan memiliki pengaruh terhadap variabel dependen.

Tabel 1. Hasil Uji Regresi Linier Berganda

\begin{tabular}{clccc}
\hline No & \multicolumn{1}{c}{ Variabel } & Koefisien & T hitung & Sig. \\
\hline 1 & Konstanta & $-3,163$ & $-3,327$ &, 001 \\
2 & Harga Cabai Rawit Merah & $1,387 \mathrm{E}-6$ & 1,148 &, 254 \\
3 & Harga Cabai Merah Keriting & $1,396 \mathrm{E}-6$ &, 135 &, 893 \\
\hline
\end{tabular}




\begin{tabular}{llccr}
\hline 4 & Pendapatan Konsumen & $9,566 \mathrm{E}-8$ & 2,910 &, 005 \\
5 & Jumlah Anggota Keluarga &, 167 & 5,504 &, 000 \\
6 & Selera Konsumen &, 889 & 9,617 &, 000 \\
\hline & F hitung $=46,332$ & & & \\
\hline Sig. $=0,000$ & & & \\
\hline
\end{tabular}

Sumber : Data Primer yang telah diolah, 2019.

Uji t menunujukkan variabel harga cabai rawit merah (X1) tidak memiliki pengaruh terhadap permintaan cabai rawit merah dan memiliki koefisien regresi 1,387E-6 bernilai positif. Setiap kenaikkan 1 satuan harga maka dapat meningkatkan permintaan cabai rawit merah sebesar 1,387E-6. Harga cabai rawit merah menunjukkan tidak berpengaruh dengan permintaan cabai rawit merah karena kenaikkan harga cabai rawit merah tidak mengurangi permintaan konsumen terhadap cabai rawit merah. Menurut Astami (2018) bahwa cabai rawit merah sudah menjadi kebutuhan konsumsi sebagai bahan masakan bagi konsumen yang menyukai masakan dengan cita rasa pedas sehingga harga tidak mempengaruhi permintaan konsumen terhadap cabai rawit merah.

Variabel harga cabai merah keriting (X2) tidak memiliki pengaruh dengan permintaan cabi rawit merah dan mempunyai koefisien regresi sebesar 1,396E-6 bernilai positif. Setiap kenaikan 1 satuan harga cabai merah keriting maka akan menurunkan permintaan terhadap cabai rawit merah sebesar 1,396E-6. Harga cabai merah keriting tidak mempunyai pengaruh terhadap permintaan cabai rawit merah karena konsumen membeli cabai merah keriting dalam jumlah yang sedikit dan terdapat konsumen yang tidak membeli cabai merah keriting sehingga harga cabai merah keriting tidak mempengaruhi permintaan cabai rawit merah. Konsumen membeli dalam jumlah sedikit dan ada yang tidak membeli cabai merah keriting karena rasasnya kurang pedas. Menurut Astami (2018) bahwa alasan konsumen tidak membeli cabai merah keriting dikarenakan cabai merah keriting memiliki rasa yang kurang pedas.

Variabel pendapatan konsumen (X3) memiliki pengaruh akan permintaan cabai rawit merah dan memiliki koefisien regresi sebesar 9,566E-8 bernilai positif. Hal ini mempunyai arti bahwa setiap kenaikkan 1 satuan pendapatan konsumen maka akan meningkatkan permintaan cabai rawit merah sebesar 9,566E-8. Pendapatan konsumen berpengaruh terhadap permintaan karena semakin tinggi pendapatan maka kuantitas permintaan cabai rawit akan meningkat. Menurut Rosalina et al. (2017) menyatakan bahwa pendapatan tinggi dapat meningkatkan pembelian cabai rawit merah untuk memenuhi kebutuhan konsumsi keluarga.

Variabel jumlah anggota keluarga (X4) memiliki pengaruh akan permintaan cabai rawit merah dan memiliki koefisien regresi sebesar.167. Nilai koefisien regresi adalah positif yang artinya setiap kenaikkan 1 satuan jumlah anggota keluarga konsumen dapat meningkatkan permintaan cabai rawit merah sebesar .167. Jumlah anggota keluarga konsumen berpengaruh terhadap permintaan cabai rawit merah karena semakin banyak jumlah anggota keluarga maka semakin banyak jumlah permintaancabai rawit merah oleh konsumen. hal ini dikarenakan permintaan cabai rawit merah oleh konsumen bertujuan untuk memenuhi kebutuhan konsumsi dari anggota keluarga konsumen. Menurut Astami (2018) 
menyatakan bahwa anggota keluarga konsumen yang banyak dapat meningkatkan permintaan cabai rawit merah untuk memenuhi kebutuhan konsumsi keluarga.

Variabel selera konsumen (X5) memiliki pengaruh atas permintaan cabai rawit merah dan memiliki koefisien regresi sebesar .889. koefisien regresi bernilai positif, artinya setiap kenaikkan 1 satuan selera konsumen maka akan meningkatkan permintaan konsumen terhadap cabai rawit merah sebesat .889 . Setiap konsumen memiliki selera masing - masing dalam hal makanan sehingga selera konsumen berpengaruh terhadap permintan cabai rawit merah. Menurut (Boediono, 2000) jika terjadi perubahan selera konsumen terhadap barang maka dapat mengakibatkan perubahan permintaan akan barang tersebut walaupun harga barang tersebut tidak mengalami perubahan. Diperkuat pendapat Rahardja dan Manurung (2008) bahwa selera dapat berubah dari waktu ke waktu akan tetapi perubahan tersebut relatif stabil dalam jangka waktu pendek.

Uji koefisien determinansi $\mathrm{R}^{2}$ mengungkap hasil nilai Adjusted $\mathrm{R}$ Square adalah 0,718 yang artinya $71,8 \%$ ragam atau perubahan permintaan cabai rawit merah dapat digambarkan dari semua variabel independen yang ditaksir memiliki pengaruh. Sebesar $28,2 \%$ sisanya, variabel dependen diterangkan dari variabel selain variabel yang telah ditentukan dan diteliti. Menurut Cahmayati dan Hadi (2009) bahwa variabel independen memberi hampir semua keterangan guna memperkirakan variabel dependen jika nilai Adjusted R Square yang mendekati satu

Tabel 2. Elastisitas Permintaan

\begin{tabular}{clc}
\hline No & \multicolumn{1}{c}{ Variabel } & Nilai Elastisitas \\
\hline 1 & Harga cabai rawit merah $\left(\mathrm{X}_{1}\right)$ & 1,354 \\
2 & Harga cabai merah keriting $\left(\mathrm{X}_{2}\right)$ & 0,122 \\
3 & Pendapatan Konsumen $\left(\mathrm{X}_{3}\right)$ & 0,317 \\
\hline
\end{tabular}

Sumber: Data Primer yang telah diolah, 2019

Nilai elastisitas menggambarkan besar perubahan jumlah komoditas yang diminta apabila dibandingkan dengan perubahan harga. Perhitungan elastisitas permintaan disajikan dalam Tabel 2.

Besarnya nilai elastisitas harga cabai rawit merah adalah 0,135. Nilai bertanda positif menerangkan variabel harga cabai rawit merah berpengaruh searah dengan permintaan cabai rawit merah. Apabila harga cabai rawit merah naik $1 \%$, permintaan cabai rawit merah juga meningkat sebesar $0,135 \%$. Permintaan cabai rawit merah bersifat inelastis karena bernilai 0,135. Menurut (Sukirno, 2008) bahwa permintaan dikatakan elastis jika nilai elastis $>1$, inelastis jika nilai elastis $<1$, unitary elastis jika nilai elastis $=1$, inelastis sempurna e $=0$ dan elastis sempurna $\mathrm{e}=\infty$. Menurut Rosalina et al. (2017) bahwa elastisitas harga cabai rawit adalah kurang dari 1 maka bersifat inelastis. Diperkuat oleh Dewi (2009) elastisitas harga mempunyai sifat inelastis dikarenakan nilai elastisitasnya kurang dari 1 yang berarti persentase perubahan jumlah yang diminta lebih kecil dari perubahan harga. Menurut Shofiatun (2017) bahwa jika barang bersifat inelastis maka persentase perubahan jumlah barang yang diminta lebih kecil daripada perubahan harga.

Besarnya elastisitas silang harga cabai merah keriting adalah 0,122; artinya apabila harga cabai merah keriting naik 1\% maka permintaan cabai rawit merah naik sebesar $0,122 \%$. Elastisitas silang mempunyai sifat inelastis dan nilai positif 
menerangkan cabai merah keriting adalah bahan pengganti dari cabai rawit merah. Sesuai pendapat Salvatore (2011) bahwa apabila nilai elastisitas silang bernilai positif maka barang X dan Y merupakan barang substitusi sedangkan apabila nilai elastisitas silang bernilai negatif maka barang $\mathrm{X}$ dan $\mathrm{Y}$ adalah barang komplementer. Sesuai pendapat Rosalina et al. (2017) bahwa jika elastisitas silang bernilai negatif maka barang tersebut bersifat komplementer. Menurut Dewi (2009) menyatakan bahwa tanda positif nilai elastisitas menunjukkan hubungan barang substitusi sedangkan tanda negatif nilai elastisitas menunjukkan hubungan barang komplementer.

Besarnya nilai elastisitas pendapatan adalah 0,317; artinya apabila pendapatan naik sebesar $1 \%$ maka permintaan cabai rawit merah akan bertambah sebanyak 0,317\%. Elastisitas pendapatan bersifat inelastis $(\mathrm{Ei}<1)$ dan nilainya positif yang menerangkan bahwa cabai rawit merah meupakan barang normal. Menurut Firdaus (2009) bahwa apabila nilai elastisitas pendapatan kurang dari 0 maka termasuk barang inferior, elastisitas pendapatan bernilai lebih dari satu termasuk barang mewah dan jika elastisitas pendapatan bernilai lebih dari 0 kurang dari 1 maka termasuk barang normal. Menurut Dewi (2009) bahwa barang tersebut termasuk barang nomal atau inelastis jika angka elastisitas pendapatan yang lebih kecil dari satu dan bertanda positif.

\section{KESIMPULAN DAN SARAN}

\section{Simpulan}

Berdasarkan hasil penelitian disimpulkan:

1. Harga cabai rawit merah, harga cabai merah keriting, pendapatan keluarga rumah tangga, jumlah anggota konsumen dan selera konsumen secara bersama - sama berpengaruh signifikan terhadap permintaan cabai rawit merah di Kabupaten Semarang. Secara parsial, pendapatan keluarga, jumlah anggota keluarga konsumen dan selera konsumen berpengaruh secara signifikan terhadap permintaan cabai rawit merah, sedangkan harga cabai rawit merah dan harga cabai merah keriting tidak berpengaruh secara signifikan terhadap permintaan cabai rawit merah.

2. Elastisitas harga cabai rawit merah bersifat inelastis dengan nilai kurang dari satu. Elastisitas silang harga cabai merah keriting bersifat inelastis dan bernilai positif yang menunjukkan cabai rawit merah termasuk barang normal dan menunjukkan bahwa cabai merah keriting merupakan barang substitusi dari cabai rawit merah. Sedangkan elastsitas pendapatan bersifat inelastis yang menunjukkan bahwa cabai rawit merah termasuk barang normal.

\section{Saran}

Setelah melaksanakan penelitian ini, maka saran yang dapat saya sampaikan adalah sebagai berikut :

1. Bagi pemerintah, penelitian ini diharapkan mampu memberikan informasi mengenai faktor - faktor yang berpangaruh terhadap permintaan cabai rawit merah. Diperlukannya analisis prediksi kebutuhan dan ketersediaan cabai rawit merah di Kabupaten Semarang supaya harga cabai rawit merah tidak melambung tinggi pada hari - hari besar. 
2. Bagi peneliti selanjutnya dengan kajian yang sama diharapkan supaya menambah variabel - variabel yang diduga berpengaruh terhadap permintaan cabai rawit merah.

\section{DAFTAR PUSTAKA}

Astami, M. T. 2018. Analisis Faktor - Faktor Yang Mempengaruhi Permintaan Cabai Rawit Merah Oleh Konsumen Rumah Tangga Di Kota Surakarta. 6, 51-61.

Badan Pusat Statistika Kabupaten Semarang. 2018. Kabupaten Semarang dalam Angka 2018. Badan Pusat Statistika, Semarang.

Boediono. 2000. Ekonomi Mikro. Badan Penerbit Fakultas Ekonomi Universitas Gadjah Mada, Yogyakarta.

Cahmayati, D. dan T. Hadi. 2009. Efektivitas Metode Regresi Robust PendugaWelsch dalam Mengatasi Pencilan pada Pemodelan Regresi Linier Berganda. Universitas Sriwijaya.

Dewi, R. T. 2009. Analisis Permintaan Cabai Merah di Kota Surakarta. Skripsi Universitas Sebelas Maret Surakarta.

Firdaus, A. 2009. Akuntansi Biaya, Edisi 2. Salemba 4, Jakarta.

Ghozali, I. 2011. Aplikasi Analisis Multivariate dengan Program IBM SPS 19. Badan Penerbit Universitas Diponegoro, Semarang.

Kuncoro, M. 2009. Metode Riset untuk Bisnis dan Ekonomi. Erlangga, Jakarta.

Palar, N. 2016. Faktor-Faktor Yang Mempengaruhi Harga Cabai Rawit Di Kota Manado. J. Agri-Sosioekonomi, 12, 105-120.

Prajnata, F. 2001. Agribisnis Cabai Hibrida. Penebar Swadaya, Jakarta.

Pusat Data dan Sistem Informasi Pertanian. 2018. Outlook Cabai. Sekretariat Jendral Kementerian Pertanian, Jakarta

Rahardja, P. dan M. Manurung. 2008. Pengantar Ilmu Ekonomi (Mikroekonomi \& Makroekonomi) Edisi Ketiga. Universitas Indonesia Press, Jakarta.

Rosalina, O. H., A. Q. Pudjiastuti dan F. Mutiara. 2017. Faktor-Faktor yang Mempengaruhi Permintaan Cabai Rawit di Desa Girimoyo Kecamatan Karangploso Kabupaten Malang. Skripsi Universitas Tribhuwana Tunggadewi.

Salvatore, D. 2011. Teori Ekonomi Mikro. Erlangga, Jakarta.

Santoso, S. 2009. Panduan Lengkap Menguasai Statistik Dengan SPSS 17. PT. Elex Media Komputindo, Jakarta.

Setiadi. 2008. Bertanam Cabai. Penebar Swadaya, Jakarta.

Shofiatun. 2017. Analisis Permintaan Cabai Merah Keriting (Capsicum annum) di Kota Semarang. J. Mediagro. $13: 79-91$. 
Sinambela, S. D., S. Ariswoyo. dan H. R. Sitepu. 2014. Menetukan Koefisien Determinasi Antara Estimasi M dengan Tipe Welsch Dengan Least Trimmed Square dalam Data yang Mempunyai Pencicilan. J. Saintia Matematika, 2, $225-235$.

Sukirno, S. 2008. Makro Ekonomi, Teori Pengantar. PT. Raja Grafindo Perkasa, Jakarta.

Yanti, N. M. S. M. 2019. Faktor-faktor yang Mempengaruhi Permintaan Konsumen terhadap Cabai Rawit di Kota Denpasar Provinsi Bali. E-Jurnal Agribisnis Dan Agrowisata, 8, 165-174.

Zaenuddin. 2015. Isu, Problematika, Dinamika Perekonomian dan Kebijakan Publik. Deepublish, Jakarta. 